4

\title{
Enhanced Anaerobic Digestion Performance via Combined Solids- and Leachate-based Hydrolysis Reactor Inoculation
}

\author{
L. Paige Wilson ${ }^{\mathrm{a} 1}$, Sybil E. Sharvelle ${ }^{\mathrm{a}}$, Susan K. De Long ${ }^{\mathrm{a}^{*}}$
}

aDepartment of Civil and Environmental Engineering,

Colorado State University, 1301 Campus Delivery, Fort Collins, CO 80523, USA

paige.wilson@colostate.edu, sybil.sharvelle@colostate.edu,susan.de_long@colostate.edu

${ }^{1}$ Present address: Hazen and Sawyer, 545 Mainstream Drive, Nashville, TN 37228, USA.

${ }^{*}$ Corresponding author. Present address: 1301 Campus Delivery, Fort Collins, CO 80523, USA.

Tel.: (970) 491-6606. E-mail: susan.de_long@colostate.edu

(1)

Abbreviations: $\mathrm{AD}^{1}, \mathrm{DWWTP}^{2}, \mathrm{OFMSW}^{3}, \mathrm{OTU}^{4}, \mathrm{MDS}^{5}, \mathrm{TAN}^{6}, \mathrm{~T}-\mathrm{RFLP}^{7}, \mathrm{~T}-\mathrm{RFs}^{8}, \mathrm{OLR}^{9}$

\footnotetext{
${ }^{1}$ Anaerobic digestion

${ }^{2}$ Drake Municipal Wastewater Treatment Plant

${ }^{3}$ Organic fraction municipal solid waste

${ }^{4}$ Operational taxonomic unit

${ }^{5}$ Non-metric multi-dimensional scaling

6 Total ammonia nitrogen

${ }^{7}$ Terminal restriction fragment length polymorphism

${ }^{8}$ Terminal restriction fragments

${ }^{9}$ Organic loading rate
} 
Suboptimal conditions in anaerobic digesters (e.g., presence of common inhibitors

21 ammonia and salinity) limit waste hydrolysis and lead to unstable performance and process

22 failures. Application of inhibitor-tolerant inocula improves hydrolysis, but approaches are

23 needed to establish and maintain these desired waste-hydrolyzing bacteria in high-solids reactors.

24 Herein, performance was compared for leach bed reactors (LBRs) seeded with unacclimated or 25 acclimated inoculum ( $0-60 \%$ by mass) at start-up and over long-term operation. High quantities

26 of inoculum $(\sim 60 \%)$ increase waste hydrolysis and are beneficial at start-up or when inhibitors

27 are increasing. After start-up ( 112 days) with high inoculum quantities, leachate recirculation

28 leads to accumulation of inhibitor-tolerant hydrolyzing bacteria in leachate. During long-term

29 operation, low inoculum quantities $(\sim 10 \%)$ effectively increase waste hydrolysis relative to

30 without solids-derived inoculum. Molecular analyses indicated that combining digested solids

31 with leachate-based inoculum doubles quantities of Bacteria contacting waste over a batch and

32 supplies additional desirable phylotypes Bacteriodes and Clostridia.

\section{KEYWORDS}

36 Anaerobic digestion, ammonia, multi-stage, salinity, leachate, inoculation, acclimation 


\section{Introduction}

39 Anaerobic digestion (AD) is an environmentally attractive technology for conversion of various wastes to energy. However, despite numerous benefits, AD applications to the organic fraction of municipal solid waste (OFMSW) remain limited in North America due to economic barriers with

42 existing technologies. To achieve economic viability, improved reactor performance is needed to 43 increase bioenergy generation. One challenge to optimizing bioenergy generation is the presence 44 of microbial inhibitors that can lead to suboptimal performance or even process failures. Food waste is highly digestable, and 83-91VS\% destruction typically can be achieved if conditions are optimal (Nagao et al., 2012; Yi et al., 2014; Zhang et al., 2007). However, elevated levels of

47 inhibitors, including ammonia and salinity, are often found in AD systems that recycle leachate

48 (Chen et al., 2008; Kayhanian, 1994; Shahriari et al., 2012). Leachate recycle leads to build up of these inhibitors, which are present in feedstocks including food waste and manure. Inhibition of AD performance due to elevated ammonia and salinity has been demonstrated to occur at concentrations $>1.7 \mathrm{~g}$ total ammonia nitrogen (TAN)/L and $3.5 \mathrm{~g} \mathrm{Na}^{+} / \mathrm{L}$, respectively (Chen et

52 al., 2008). Leachate recycle may be employed to retain methanogens in single-stage AD

53 configurations and to reduce water usage in both single- and multi-stage systems. Thus,

54 strategies are needed to maintain high energy generation even when inhibitors are present.

Multi-stage AD technologies are advantageous because these systems use separate reactors for each stage, allowing for individual optimization of hydrolysis and methanogenesis

57 processes (Voelklein et al., 2016). For OFMSW, hydrolysis is preferably conducted in leach bed reactors (LBRs) operated in dry batch mode because LBRs can accept high solids waste ( $>15 \%$ solids) (Mata-Alvarez et al., 2000). Methanogenesis is conducted in high-rate reactors including 60 fixed film (FF) or upflow anaerobic sludge blanket (UASB) reactors (Najafpour et al., 2006). 
61 Numerous studies have focused on improving methanogenesis under inhibitory conditions (Chen

62 et al., 2008), but studies focused on enhancing hydrolysis in the presence of inhibitors are

63 lacking. Hydrolysis is the first and often rate-limiting step in high-solids anaerobic digestion $(\mathrm{Xu}$

64 et al., 2011). Thus, advancements in hydrolysis processes have the potential to improve AD

65 performance and economic viability.

Previous research has demonstrated that hydrolysis rates can be increased in the presence

67 of elevated ammonia and salinity via inoculation (Wilson et al., 2013). Further, inoculum

68 acclimation has been shown to enhance hydrolysis rates in wet reactors treating food waste and

69 manure by selecting for optimal microbial communities capable of performing under inhibitory

70 conditions (Wilson et al., 2013). However, inoculation with hydrolyzers is not used in practice in

71 high-solids systems. Since the quantity of microorganisms in LBRs can limit reactor

72 performance, establishing and maintaining desirable microbial communities in reactors is key to

73 optimal operation. To promote establishment of desirable microorganisms in LBRs, acclimated

74 inoculum may be used as initial seed. After start-up, LBRs may benefit from re-inoculation with

75 each new batch because substantial time (several days to weeks) is required to develop inhibitor-

76 tolerant hydrolyzing bacterial communities (Wilson et al., 2016). Thus, development of

77 successful inoculation approaches for high-solids systems is needed.

78 To maintain desired microorganisms in AD systems, inocula derived from previously

79 digested waste are promising because surface-attached bacteria are known to mediate hydrolysis

80 of the recalcitrant feedstock cellulose (Wang et al., 2010). Digested waste inoculum has been

81 shown to increase hydrolysis rates in LBRs under low ammonia conditions. Xu et al. (2012)

82 recommended $20 \%$ inoculum (by mass) for LBRs, although that study used artificial food waste

83 and LBRs were run in isolation (i.e., not connected to methanogenesis reactors). Another study 
84 suggested leachate recycle (as opposed to single pass) may provide inoculum for improving 85 process performance in LBRs treating manure (El-Mashad et al., 2006). By contrast, Degueurce et al. (2016) suggested that the beneficial role of leachate recirculation in LBR-based AD is abiotic and mainly due to leachate nutrient content, $\mathrm{pH}$, and buffering capacity. However, none of these studies investigated the impact of inhibitors, and studies only examined one batch period. Thus, further research was needed to investigate optimal inoculation approaches and amounts for post-consumer waste in multi-stage systems during start-up and long-term operation with elevated ammonia and salinity.

Optimal inoculation approaches, including use of digested waste inoculum or leachate recycle, will most readily be developed with a fundamental understanding of the composition and distribution of microbial communities present in digested waste, leachate and fresh waste. Different microbial communities are selected for as a function of different reactor conditions including inhibitor concentrations and feedstock (Wilson et al., 2013). Thus, by extension, microbial communities are expected to differ substantially between digested waste, leachate and fresh waste, but the distribution and composition of microbial communities in multi-stage $\mathrm{AD}$ systems over long-term operation has yet to be investigated. This knowledge will support optimization of operational methods, potentially leading to improved economic viability via increased methane production, or reduced reactor volumes and batch times.

Thus, the objectives of this study were to (1) evaluate initial and long-term inoculation methods to establish enriched inhibitor-tolerant hydrolyzing communities and enhance performance of LBRs, and (2) to advance understanding of hydrolyzing microbial communities in multi-stage $\mathrm{AD}$ systems. The approach was to operate laboratory-scale, multi-stage $\mathrm{AD}$ systems fed post-consumer OFMSW under elevated ammonia and salinity conditions. The 
107 impact of operational approaches on hydrolysis performance was investigated by comparing

108 performance for LBRs seeded with unacclimated inoculum and different ratios of acclimated

109 inoculum at start-up. Additionally, the effect of seeding methods was examined during long-term

110 operation by identifying the optimal ratio of fresh waste to previously digested waste in multi-

111 stage systems incorporating leachate recycle. Molecular tools (e.g., terminal restriction fragment

112 length polymorphism [T-RFLP] and 16S rRNA gene amplicon sequencing) were utilized to track

113 microbial community development in the inoculum, feedstock, and leachate.

114 2. Materials and Methods

115 2.1. Feedstock and inoculum collection

116 The OFMSW feedstock utilized in this study was a combination of food and yard waste.

117 Food waste was collected from the Colorado State University Ram's Horn dining facility as

118 previously described; in this facility, food waste is separated, pulped and de-watered (Wilson et

119 al., 2013). Pulped waste was used to produce a homogenized waste and increase reproducibility.

120 Characterization of this food waste source also has been previously reported (Wilson et al.,

121 2013). Food waste was stored in bins for less than 2 days prior to experimental use. Yard waste

122 (leaves and grass clippings) and wood chips (used as a bulking material) were collected from a

123 local landscaping company (Hageman Earth Cycle, Fort Collins, CO). In high-solids AD

124 systems, a bulking agent must be added to promote optimal hydraulics (Xu e al., 2011). After

125 collection, OFMSW was stored at $4{ }^{\circ} \mathrm{C}$ until subsequent use the following day. Immediately prior

126 to experimental use, food waste ( $82 \%$ by wet mass), grass clippings ( $7.25 \%)$, leaves $(3.5 \%)$, and

127 wood chips (7.25\%) were mixed thoroughly by hand to create the OFMSW feedstock loaded into

128 LBRs. This food waste to yard waste ratio is consistent with ratios that may be used in the field

129 (Beanie, 2013). Original microbial inoculum was collected from the Drake Municipal 
130 Wastewater Treatment Plant (DWWTP) mesophilic anaerobic digester (Fort Collins, CO) and

131 used immediately after collection. Waste and inoculum were analyzed for total and volatile

132 solids (TS and VS, respectively) content prior to digestion (Table S1).

\section{$133 \quad$ 2.2. Reactor configurations}

\subsubsection{Start-up test configuration}

Two different configurations were used in this study to investigate the effects of inoculum percentage at start-up and over time. For experiments focused on reactor start-up, 4

137 LBRs were connected to individual leachate storage tanks (LSTs) (Fig. 1a). In this set-up, the 138 LSTs were not connected to methanogenic reactors and instead recycled leachate directly to the top of the LBRs. Methanogenic reactors were not used to simplify the experimental setup and

140 because hydrolysis was the study focus. Utilizing separate LSTs allowed for isolation of the 141 effects of inoculum percentages without the influence of microbial community development

142 from the other LBRs or methanogenic reactors. LBRs were clear polycarbonate pipe with a 143 diameter and height of $20 \mathrm{~cm}$ and $91 \mathrm{~cm}$, respectively. The LBRs were sealed with Cherne 144 adjustable pipe caps that were fitted with 5 evenly-spaced ports for leachate distribution (Fig.

145 1b). The volume of waste in each LBR varied depending on the percentage of inoculum used and 146 was $\sim 10-25 \mathrm{~L} .19 \mathrm{~L}$ plastic carboys ( $\sim 15 \mathrm{~L}$ leachate) were utilized as LSTs. Leachate from each 147 LBR was gravity-fed into an individual LST, and then pumped (via Cole Parmer Masterflex L/S 148 Digital Drive peristaltic pumps) back to the top of the LBR at a rate of $20 \mathrm{ml} / \mathrm{min}$. Flow rates 149 were digitally controlled, and the accuracy of the flow rate was manually confirmed three times 150 during the experimental period. $1.27 \mathrm{~cm}$ and $0.32 \mathrm{~cm}$ vinyl tubing (inside diameter) were used 151 for leachate delivery to the LSTs and LBRs, respectively. LBRs were refilled every 16 days. A 152 relatively short (16-day) batch digestion period was selected to investigate the impact of 
153

154

155

156

157

158

159

160

161

162

163

164

165

166

167

168

169

170

171

172

173

174

175

operational changes during the early to middle portion of a digestion period; batch digestion times of $\sim 3$ weeks are common at full scale.

\subsubsection{Long-term operation configuration}

For long-term operation, a multi-stage system was utilized that contained a triplicate set of LBRs (previously described in Section 2.2.1), 1 LST (54.6 cm x $38.1 \mathrm{~cm}$ x $66 \mathrm{~cm}$ ), and 1 fixed film reactor (cylindrical drum with a radius and height of $23 \mathrm{~cm}$ and $79 \mathrm{~cm}$, respectively) (Fig. 1c). The LST and FF had working volumes of $\sim 38$ and $114 \mathrm{~L}$, respectively. Leachate from the 3 LBRs flowed into $1 \mathrm{LST}$ and then was pumped to the $\mathrm{FF}$ at a rate of $9 \mathrm{ml} / \mathrm{min}$. Effluent from the FF was pumped at the same rate back to the LST. Leachate also was pumped from the LST to the top of the LBRs as described in Section 2.2.1. Vinyl tubing (1.27 cm inside diameter) was used for leachate delivery to and from the FF. The FF was filled with plastic packing material (Bioportz moving media, Entex Technologies). Leachate samples for liquid analysis were collected from the LST and FF reactor effluent (post-treatment). Samples were collected from the LST, rather than LBR effluent directly, as a means of monitoring $\mathrm{pH}$ and volatile fatty acid (VFA) concentrations in the composited leachate delivered to the LBRs and FF to determine if pH and VFA concentrations were inhibitory (e.g., >6.5 pH in the LST) (Ahn et al., 2010). pH and VFA levels were not found to be inhibitory at any point during operation.

\subsection{Microbial acclimation for LBRs and FF}

To develop a large volume of acclimated inoculum to seed LBRs for tests under elevated ammonia and salinity concentrations, 2 LBRs were loaded with $3600 \mathrm{~g}$ (wet weight) of OFMSW and inoculated with DWWTP AD sludge ( $20 \%$ of total material by mass) by layering (Section 2.1) (Fig. 1d, Table S1). During digestion, leachate generated was collected in one LST (initially filled with nitrogen-purged deionized [DI] water) and recirculated back to the top of each LBR 
176 using the configuration in Fig. 1a. Leachate was analyzed at least twice a week for dissolved

177 chemical oxygen demand (DCOD), VFAs, ammonia, pH, and electrical conductivity (EC). After

178 the first batch (16 days), the LBRs were emptied and refilled by layering fresh waste with

179 previously digested waste (60\% wet weight). Fresh waste and inoculum were alternately layered

180 (4 and 5 layers of fresh waste and inoculum, respectively) to provide contact between waste and

181 inoculum; layers were separated by mesh $(5 \mathrm{~mm})$ so that they could be distinguished post-

182 digestion. Fresh waste layers were $900 \mathrm{~g}$ (wet weight) each, and the mass of inoculum layers

183 varied depending on the inoculum percentage utilized. Columns were purged with nitrogen gas

184 after each refilling to avoid prolonged exposure of the inoculum to oxygen. LBRs were operated

185 over a 16-week period, and ammonia and salinity concentrations in leachate gradually were

186 elevated artificially to $3.5 \mathrm{~g}$ TAN/L and a conductivity of $45 \mathrm{mS} / \mathrm{cm}$ (surrogate measure of

187 salinity, $\left.\sim 6 \mathrm{~g} \mathrm{Na}^{+} / \mathrm{L}\right)$, respectively, by adding ammonium chloride and sodium chloride.

188 Acclimation was considered complete when final solids destruction did not vary by more than

$18910 \%$ for consecutive batches.

To acclimate a microbial inoculum for the FF reactor (Fig. 1c), AD sludge was incubated

191 at $35^{\circ} \mathrm{C}$ for 2 weeks and fed glucose while the ammonia and salinity concentrations were

192 increased gradually to $1.5 \mathrm{~g}$ TAN/L and $3 \mathrm{~g} \mathrm{Na}^{+} / \mathrm{L}$ using ammonia chloride and sodium chloride.

193 Next, the inoculum was mixed with a nutrient solution (50\% v/v basis) (Owen et al., 1979) to

194 ensure that nutrients were not limiting in the system, and the reactor was fed glucose or leachate

195 generated from the LBRs at an organic loading rate $(\mathrm{OLR})$ of $1 \mathrm{~g} \mathrm{COD} / \mathrm{L} \cdot$ day while ammonia

196 and conductivity concentrations were slowly increased further to $3.5 \mathrm{~g}$ TAN/L and $45 \mathrm{mS} / \mathrm{cm}$. A

197 low OLR was used during acclimation to prevent the build-up of VFAs in the FF in the case that

198 conversion of VFAs to methane was slow due to the increasing ammonia and salinity 
concentrations. The effluent was recycled continuously at a rate of $50 \mathrm{ml} / \mathrm{min}$, and the $\mathrm{pH}$ was adjusted to 7 using $\mathrm{NaOH}$ as needed. Throughout the 16-week period, the methanogenic reactor was operated as a "wet" (low-solids) digester (i.e., recycled liquid flowed through a sludge of suspended biomass) rather than as a FF reactor to avoid sub-optimal microorganisms (noninhibitor-tolerant microorganisms) attaching to the plastic packing. After 16 weeks, packing material was added to the reactor, and the FF reactor was operated for 3 weeks prior to subsequent experiments.

\subsection{Reactor operation}

\subsubsection{Determining optimal seeding methods at start-up}

To determine optimal seeding methods at start-up or when inhibitors become elevated, LBRs operating under elevated ammonia and salinity (3.5 g TAN/L and $45 \mathrm{mS} / \mathrm{cm}$, respectively) were seeded by layering initially with unacclimated ( $60 \%$ by wet mass) or different percentages of acclimated inoculum $(60 \%, 10 \%$, and $0 \%$ by mass $)$ and operated for a total of 3 batches with the set-up described in Section 2.2.1 (Fig. 1a, d). In full-scale systems that incorporate recycle, it can take many batches ( months of operation) for inhibitors to build up in leachate. Thus, ammonia and salinity were artificially elevated using ammonium chloride and sodium chloride as described in Sections 2.3. to accelerate our study. The unacclimated inoculum utilized was previously digested waste from an identical multi-stage system operating under low ammonia and salinity. The source of acclimated inoculum was previously digested waste from the acclimated LBRs (Section 2.3). For all 3 batches, the mass of fresh waste (3600 g) loaded into each LBR remained constant. Since a FF reactor was not utilized in this set-up, leachate was manually diluted $50 \%$ by volume daily (Xu et al., 2011) with nitrogen-purged DI water to simulate the FF function (i.e., to reduce the concentration of soluble organics typically consumed 
222 in the FF). The DI water was spiked with appropriate concentrations of ammonium chloride and

223 sodium chloride to maintain elevated ammonia and sodium in the system.

224 2.4.2. Determining optimal seeding methods over time

225 To determine the optimal ratio of previously digested waste to fresh waste over time,

226 LBRs operating under elevated ammonia and salinity were seeded initially with a high

227 percentage (60\% by mass) of acclimated inoculum with the set-up described in Section 2.2.2

228 (Fig. 1c). After each batch (16 days), the LBRs were emptied and refilled with fresh and

229 previously digested waste as described in Section 2.3. LBRs were reseeded with decreasing

230 percentages of inoculum $(40 \%, 20 \%, 10 \%$, and $0 \%)$ to determine the minimum amount of

231 inoculum needed to maintain optimal microorganisms in the system. For each inoculum

232 percentage, LBRs were operated for 2 (at $60 \%, 20 \%$, and $0 \%$ inoculum) or 3 (at $40 \%$ and $10 \%$

233 inoculum) batches. Post-digestion, separate inoculum and digested waste layers were mixed

234 thoroughly by hand for 5 minutes, and 5 random samples were analyzed for TS and VS. Thus,

235 for each inoculum percentage, hydrolysis performance results were based on a minimum of 30

236 samples ( 3 columns x 2 batches x 5 samples).

237 2.5. Chemical analyses

TS and VS of the inoculum and waste were measured pre- and post-digestion according

239 to Standard Method 2540 (APHA, 1995). TS and VS removal efficiencies were calculated

240 according to $\mathrm{Xu}$ et al. (2011). Liquid samples extracted from the LST and FF effluent were

241 analyzed for $\mathrm{pH}$ and EC using probes (VWR \#89231-604 and \#11388-382, respectively). DCOD

242 concentrations were determined using Hach's COD High Range Vials and digestion colorimetric

243 method (Hach, Loveland, CO). VFAs were determined using Hach's Volatile Acids TNTplus

244 Reagent Set and esterification method. Samples were filtered through a $0.2 \mu \mathrm{m}$ syringe filter 
245 prior to DCOD and VFA analyses. Hach's Nitrogen-Ammonia High Range Reagent Set was

246 utilized weekly to verify that ammonia concentrations remained constant over time. Biogas

247 volume was measured utilizing a wet tip gas meter (Speece Co., Nashville, TN), and biogas

248 composition was determined via gas chromatography using a thermal conductivity detector as

249 described previously (Wilson et al., 2013).

250 2.6. Microbial community analyses

251

Motivated by the long-term study results, experiments were conducted to compare

252 quantities and compositions of the microbial communities among the leachate, inoculum, and

253 fresh waste. Samples used for quantification of Bacteria in leachate and previously digested

254 inoculum were collected on day 192 of the long-term experiment. To prepare samples for DNA

255 extraction, $50-\mathrm{ml}$ leachate samples were centrifuged at $5,000 \mathrm{~g}$ for 10 minutes at $4^{\circ} \mathrm{C}$. The

256 supernatant was discarded, and the remaining pellet was used for DNA extraction. For solid

257 samples, $25 \mathrm{~g}$ of fresh waste or inoculum were blended with $125 \mathrm{ml}$ of sterile DI water for 1

258 minute to ensure representative samples. The blended mixture was then centrifuged at $5000 \mathrm{~g}$ for

2595 minutes at $4^{\circ} \mathrm{C}$. The supernatant was discarded, and the pellet was used for DNA extraction.

260 For all samples, DNA was extracted using MoBio's PowerSoil ${ }^{\circledR}$ DNA isolation kit according to

261 the manufacturer's instructions.

262 Bacterial 16 rRNA genes were quantified by qPCR generally according to previously

263 described methods. Details are provided in supplemental information. For all inoculum

264 percentages, bacterial 16S rRNA gene quantities were estimated based on a single sample (192-

265 day sample) to eliminate the impact of changes over time. The number of 16S rRNA genes per

266 mass of solid inoculum was determined, and the total quantity of Bacteria added to the LBRs

267 was projected for each inoculum percentage. All numbers are expressed as a function of the 
268 amount of fresh waste added, which was constant over time. For leachate, the quantity of 16S

269 rRNA genes was determined per volume of leachate, and multiplied by the amount of leachate

270 distributed to the LBRs over the experimental period.

271 Community composition was determined via T-RFLP analyses of DNA isolated from

272 leachate, fresh waste, and previously digested inoculum and waste. Previously digested waste

273 was collected from three LBRs operated with fresh waste and inoculum (40\% by mass) layered

274 (LI), fresh waste and inoculum (40\% by mass) thoroughly mixed by hand (MI), and fresh waste

275 only with no inoculum (NI) utilizing the set-up described in Section 2.2.2. To determine

276 microbes present early in the batch period, digested samples were extracted from each layer of

277 the LBRs after 5 days of operation; leachate and previously digested inoculum samples were

278 collected as described above. To track changes to bacterial, fermenting, and hydrolyzing

279 communities, T-RFLP analyses were conducted targeting the 16S rRNA gene, hydA gene

280 (encodes the alpha subunit of iron hydrogenase), and cel48 gene (encodes glycoside hydrolases

281 of family 48). T-RFLP analysis targeting the 16S rRNA gene was conducted as described by

282 Wilson et al. (2013). T-RFLP analyses targeting the hydA gene and cel48 gene were conducted

283 as previously described by Lefèvre et al. (2013).

284

DNA from leachate (collected on day 192), fresh waste, and inoculum (collected on day

285 192) were submitted to Research and Testing Laboratories LLC (Lubbock, Texas) for bacterial

286 16S rRNA gene amplicon sequencing using Illumina MiSeq. Primers 28f and 388R were used,

287 targeting the V1-V2 hypervariable regions of 16S rRNA genes (Sundquist et al., 2007;

288 Turnbaugh et al., 2009). Bioinformatic analysis is described in the supplemental information.

289 2.7. Statistical analyses 
Analysis of variance (ANOVA) and Tukey's Honest Significant Difference (HSD) tests

291

292

293

294

295

296

297

298

299

300

301

302

303

304

305

306

307

308

309

310

311

312

were conducted using R Statistical Software (R Core Team, 2012) to determine if the slope of

the fitted regression line for VS reduction as a function of inoculum percentage was statistically different from 0 as well as to determine statistical differences in average VS reduction for a range of inoculum percentages. Results yielding a p-value less than 0.05 were considered to be significant. T-RFLP data were analyzed and similarity matrices were calculated according to Wilson et al. (2013), except terminal restriction fragments (T-RFs) representing less than 1\% of the total area were excluded (Rees et al., 2004). Pairwise distances were calculated on aligned sequences, followed by clustering and estimation of Shannon diversity.

\section{Results and Discussion}

\subsection{Impact of inoculum percentage on waste hydrolysis at start-up}

We hypothesized that waste reduction would be limited by the number of organisms provided as inoculum in the LBRs under elevated ammonia and salinity conditions. As expected, results demonstrated that higher percentages of inoculum are beneficial and improve VS reduction. Initially, with acclimated inoculum at $60 \%$ and a digestion period of 16 days, reactors demonstrated an average VS reduction of $69.5 \%( \pm 3.5)$ (Fig. 2a). Results from our study demonstrated that hydrolysis performance was better than or comparable to previously reported performances for dry digesters operating under lower ammonia and salinity, despite the elevated levels present. For example, Xu et al. (2014) achieved 45.4 - 69.4\% VS reduction in LBRs treating food waste inoculated with WWTP AD sludge with a 16-day residence time. Similarly, Yan et al. (2014) demonstrated 58.7 - 68.1\% VS reduction in LBRs fed simulated food waste and inoculated with AD sludge and cow manure. Lu et al. (2008) demonstrated 63\% VS reduction in LBRs connected to a UASB with leachate recirculation treating vegetable and 
313 flower waste over a 10 day period. Thus, results indicated that high solids conversion can be

314 achieved even in the presence of inhibitors, if required organisms are provided in sufficient 315 quantities via inoculation.

316 For a lower acclimated inoculum percentage $(10 \%)$ or for no inoculum $(0 \%)$, average VS

317 reduction was reduced 1.5- and 2-fold, respectively (Fig. 2a). An ANOVA test on triplicate

318 batches at each inoculum percentage indicated that significant differences exist among means for

319 VS reduction $(\mathrm{p}$-value $=0.0001)$. The significant reduction in solids removal with reduced

320 inoculum percentages demonstrates that the quantity of hydrolyzing bacteria present in LBRs

321 limits performance. VS reduction improved by the end of batch 3 for all inoculum percentages

322 (with VS reduction increasing to $73 \%$ for the $60 \%$ acclimated inoculum). Performance increases

323 for successive batches likely indicate that the concentration of inhibitor-tolerant hydrolyzing

324 bacteria increased in the systems (e.g., in the digestate). However, VS reduction with 0\%

325 inoculum was still 1.9-fold lower than VS reduction with $60 \%$ inoculum for the third batch. In

326 the only other study to investigate the impact of inoculum percentage at start-up in LBRs, Xu et

327 al. (2012) also observed a decrease in waste hydrolysis with reduced inoculum percentages

$328(80 \%, 20 \%, 5 \%$, and $0 \%)$, albeit a less dramatic trend than observed in our study. The less

329 dramatic decrease was likely because Xu et al. (2012) investigated low ammonia and salinity

330 conditions. Specifically, their study demonstrated 1.13- and 1.14-fold lower VS removals for

331 inoculum percentages of $20 \%$ and $5 \%$, respectively, compared to an inoculum percentage of

$33280 \%$. Xu et al. (2012) recommended a 20\% inoculum; however, the study did not test multiple

333 batches over time or $10 \%$ inoculum. Ultimately, the substantial reduction in VS removal

334 observed in our study at lower inoculum percentages suggests that higher volumes of acclimated 
335 inoculum are needed at start-up, or when salinity and ammonia are observed to increase in 336 leachate, for optimal performance.

To determine if acclimated inoculum enhanced performance compared to unacclimated

338 inoculum, both inocula were tested in parallel at 60\%. Interestingly, acclimated inoculum

339 initially demonstrated $68 \%$ VS reduction, compared to $56 \%$ VS reduction for unacclimated

340 inoculum (Fig. 2a). However, both reactors performed similarly by the end of batch 3 . Thus,

341 results suggest that inhibitor-tolerant organisms accumulated in as little as 3 batches when a high

342 quantity of inoculum was used (60\%). Several studies have demonstrated that acclimated

343 inoculum performs better than unacclimated inoculum in wet systems (Calli et al., 2005; Chen et

344 al., 2008; Omil et al., 1995; Sung \& Liu, 2003). For example, we previously demonstrated that

345 an AD sludge-derived inoculum acclimated to elevated ammonia ( $5 \mathrm{~g}$ TAN/L) fed manure and

346 food waste performed significantly better than unacclimated sludge directly exposed to elevated

347 ammonia concentrations in wet batch reactors (Wilson et al., 2013). Thus, results herein extend

348 this finding to LBRs, although performance improvements were marginal in the high-solids

349 system. Additionally, data provide guidance on the quantity of inoculum needed to maximize

350 solids reduction at start-up ( 40-60\%) or when inhibitors build up.

351

3.2. Impact of inoculum percentage on system performance during long-term operation

To determine how inoculum percentages and connection to a FF affect maintenance of

353 desired organisms and performance over long-term operation, experiments were conducted with

354 multi-stage reactors that incorporated leachate recycle for over 190 days. Reactors were only run

355 with acclimated inoculum because results of the start-up experiments indicated that microbial

356 populations within the hydrolysis reactors seeded with unacclimated inoculum acclimated to

357 inhibitors over only three batches. Hydrolysis performance and methane generation were 
monitored across a range of inoculum percentages $(60 \%-0 \%)$. Average VS reduction for LBRs with low ammonia and salinity at $60 \%$ inoculum was slightly better (1.17-fold) than for LBRs with high ammonia ( 3.5 g TAN/L) and salinity $(45 \mathrm{mS} / \mathrm{cm})$ (Fig. 2b). This slight inhibition is consistent with the observations of others (Chen et al., 2008); however, in our study inhibition likely was minimized via the usage of acclimated inoculum. In one of the first studies to determine the effects of elevated ammonia, Kayhanian (1994) demonstrated that high solids digesters performed best at TAN concentrations in the range of 0.6-1 g/L. More recently, Duan et al. (2012) reported significant inhibition at 3 - $4 \mathrm{~g}$ TAN/L in high solids AD of sewage sludge with the highest VS reduction reaching only $40 \%$ (compared to $\sim 60 \%$ for uninhibited reactors) and VFA concentrations exceeding $10 \mathrm{~g} / \mathrm{L}$ (Song et al., 2004). In contrast, our study demonstrated VS reduction levels up to an average of $62( \pm 7) \%$ at $60 \%$ inoculum under elevated ammonia and salinity, indicating a benefit for use of inoculums acclimated to elevated ammonia and salinity.

Interestingly, in contrast to start-up, over time VS reduction remained relatively constant for decreasing inoculum percentages (Fig. 2b). At 60\% initial inoculum, VS reduction averaged $62( \pm 7) \%$ over the first two batches. When inoculum percentages were then decreased to $40 \%$ and $20 \%$, VS reduction appeared to decrease slightly. Unexpectedly, VS reduction increased to an average of $67( \pm 7) \%$ when the inoculum percentage was lowered further to $10 \%$, which was the highest VS reduction demonstrated for any of the percentages. Moreover, this performance at $10 \%$ inoculum is comparable to performance demonstrated in reactors operating under low ammonia and salinity. However, at $0 \%$ inoculum, VS reduction once again decreased and demonstrated the lowest reductions of any inoculum percentages. Despite a decreasing trend for VS reduction as a function of inoculum percentage (with the exception of $10 \%$ inoculum), the 
381 slope of the linear regression for all percentages with acclimated inoculum was not significantly

382 different from zero, suggesting that inoculum percentage did not substantially affect VS

383 reduction over time. However, an ANOVA test revealed significant differences in mean VS

384 reductions among the various inoculum percentages ( $\mathrm{p}$-value $=0.0074)$, and Tukey's HSD test

385 identified significant differences between the mean VS reduction at $10 \%$ and $0 \%$ inoculum (p-

386 value $=0.003$ ). No other significant differences between mean VS reductions were observed.

387 Thus, regardless of inoculum percentage, over time reactors demonstrated VS reduction

388 comparable to systems running under optimal conditions despite the elevated ammonia and

389 salinity levels (Lu et al., 2008; Xu et al., 2014; Yan et al., 2014).

Consistent with solids reduction data, VFA concentrations demonstrated steady

391 performance for decreasing inoculum percentages over time (Fig. 3a). At the start of a new

392 batch, leachate VFA concentrations spiked in the LST due to the influx of fresh waste but

393 gradually reduced as readily hydrolysable substrates were converted to soluble products and

394 methane. Steady, low VFA concentrations in FF effluent demonstrated the FF was effective

395 despite elevated inhibitor levels. $\mathrm{pH}$ values ranged from $6.6-8.3$ and $7.8-8.5$ in the LST and FF

396 effluent, respectively, over the course of the experiment (Fig. S1).

Overall, our reactors demonstrated comparable or higher methane generation to previous

398 literature values for reactors operating under low ammonia and salinity conditions (Fig. 3b). The

399 highest average methane yield, observed with the greatest inoculum percentage, was $0.260[ \pm$

$400 \quad 0.01] \mathrm{L} \mathrm{CH}_{4} / \mathrm{g} \mathrm{VS}_{\text {fresh waste }}$ (Fig. 3b). By contrast, lower methane production (0.182 L CH4/ g

401 VS) has been demonstrated in LBRs coupled with a UASB fed simulated food waste for a 17-

402 day digestion period at start-up (Xu et al., 2011). Additionally, Han et al. (2002) observed 0.27 L

$403 \mathrm{CH}_{4} / \mathrm{g}$ VS for sequential batch, two-phase anaerobic composting systems fed food waste (with 
impurities removed) and inoculated with rumen microorganisms with a 10 day solids retention time. Dearman et al. (2007) demonstrated similar or slightly lower methane yields $(0.214,0.229$

$\mathrm{L} \mathrm{CH}_{4} / \mathrm{g}$ VS) for dry food waste digesters using $10 \%(\mathrm{w} / \mathrm{w})$ inoculum despite an extremely long digestion period ( 73 days). Further, herein $48-63 \%$ of the theoretical methane yield was achieved based on measured biochemical methane potential ( $\left.0.41 \mathrm{~L} \mathrm{CH}_{4} / \mathrm{g} \mathrm{VS}\right)$ previously reported for the source of food waste use (Wilson et al., 2013), which is similar to food waste methane potentials reported by others (Cho et al., 1995; Lin et al., 2011). Higher percentages of the theoretical yields ( $>55 \%)$ were observed in reactors operating under $60 \%$ and $10 \%$ inoculum, whereas reactors operating under 40,20 , and $0 \%$ demonstrated $\leq 52 \%$ of theoretical yields. Yields could be increased by increasing digestion time (e.g., to 3 weeks). Additionally, the methanogenic $(\mathrm{FF})$ reactor was likely not fully optimized because hydrolysis was the focus on this study. However, achieved yields were similar to those reported by others $(47-85 \%)$ (Carucci et al., 2005; Davidsson et al., 2007; Voelklein et al., 2016) despite suboptimal reactor conditions. Solids reduction is strongly impacted by feedstock composition, and thus lower rates reported by others may also be due, in part, to use of more recalcitrant feedstocks. However, superior microbial populations likely improved methane production herein.

Interestingly, despite remaining within the range of reported methane yields, average yields in our study decreased with decreasing inoculum at $40 \%$ and $20 \%(0.212[ \pm 0.01]$ and $0.195[ \pm 0.01] \mathrm{L} \mathrm{CH}_{4} / \mathrm{g}$ VSfresh waste, respectively), but then increased at $10 \%$ inoculum and decreased at $0 \%$ inoculum, consistent with solids reduction data (Fig. 3b). At 10\% inoculum, methane yield was $0.230( \pm 0.02) \mathrm{L} \mathrm{CH}_{4} / \mathrm{g} \mathrm{VS}_{\text {fresh waste, }}$ and at $0 \%$ inoculum yield was 0.207 $[ \pm 0.01] \mathrm{L} \mathrm{CH}_{4} / \mathrm{g} \mathrm{VS}_{\text {fresh waste). }}$. Thus, collectively our results suggest that after an initial start-up period, low quantities of solid inoculum $(\sim 10 \%)$ are sufficient under elevated ammonia and 
427 salinity, and importantly, that even after start-up, solid-phase inoculum addition improves

428 performance relative to no inoculum. The increase in performance observed at $10 \%$ was

429 unexpected considering the declining trend for higher percentages and the idea that hydrolyzers

430 are solids-associated (Wang et al., 2010; Zhang et al., 2007). These results led us to hypothesize

431 that desired microorganisms built up in the leachate over time, and thus leachate recirculation

432 could also provide a source of hydrolyzing bacteria. Similarly, others have speculated that

433 leachate recirculation enhances performance based on results from a high-solids, single-stage AD

434 system fed cattle waste operated at $40^{\circ} \mathrm{C}$ and $50^{\circ} \mathrm{C}$ (El-Mashad et al., 2006). To test this

435 hypothesis and develop a mechanistic understanding of microbial community dynamics in multi-

436 stage AD systems, bacterial communities were characterized over long term operation.

437 3.4. Quantification of leachate-derived and solids inoculum bacteria

438 We sought to determine if leachate recirculation could provide a source of hydrolyzing

439 bacteria and first quantified Bacteria in the leachate and solid waste inoculum to determine how

440 the quantities of Bacteria present compared. qPCR data revealed $60 \%$ inoculum resulted in the

441 addition of $3.1 \times 10^{11}$ bacterial $16 \mathrm{~S}$ rRNA genes/ $\mathrm{g}$ fresh waste to the LBR (without including

442 bacteria contributed by leachate), while $10 \%$ inoculum provided $2.3 \times 10^{10}$ bacterial genes/ $\mathrm{g}$ fresh

443 waste (Fig. 4). Interestingly, data indicate that the quantity of Bacteria in $10 \%$ inoculum

$444\left(2.3 \times 10^{10} 16 \mathrm{~S}\right.$ rRNA genes/ $g$ fresh waste $)$ and in the leachate ( $0 \%$ inoculum) after 192 days of

445 operation $\left(2.1 \times 10^{10} 16 \mathrm{~S}\right.$ rRNA genes/ $\mathrm{g}$ fresh waste) are very similar. These data are $16 \mathrm{~S}$ rRNA

446 gene-based and thus do not indicate the type or activity of Bacteria, but these results support the

447 hypothesis that leachate is a good source of inoculum for hydrolysis after sufficient time has

448 allowed microorganisms to build up in the leachate. Notable improvements in performance were

449 not seen until day 112 , so a high percentage of inoculum may be beneficial initially for at least 2- 
4504 batches. The inoculum initial percentage used likely will affect the number of batches required

451 to establish sufficient hydrolyzing populations because high initial volumes of inoculum will add

452 greater quantities of microorganisms to the system. The inoculum percentage could also be

453 decreased slowly after 2 batches as was done here to continue building up desired organisms, and

454 simultaneously avoid system overload by slowly introducing higher quantities of OFMSW.

455 Further work is necessary to clarify the most advantageous method of decreasing inoculum over

456 time. However, within $\sim 3-4$ months, results suggest that low volumes of inoculum may be

457 utilized consistently. Importantly, molecular data also indicate that addition of 10\% inoculum

458 doubles the quantity bacteria that contact fresh waste over the course of a batch; this finding is

459 consistent with the superior performance observed at 10\% inoculum compared to leachate alone.

460 3.4.2. Microbial community composition dynamics

461 Because the type, as well as the quantity, of Bacteria control performance, we sought to

462 determine if microbial community compositions between the solid inoculum and leachate after

463192 days of operation were similar. Thus, we examined the total bacterial (via 16S rRNA gene-

464 targeted T-RFLP), fermenting (via hydA gene-targeted T-RFLP), and hydrolyzing (via cel48

465 gene-targeted T-RFLP) microbial communities among fresh waste, leachate, and inoculum.

466 Additionally, digested samples were analyzed after a 5 day digestion period to determine

467 microbes present at the early stages of a batch.

Ribosomal and functional gene-targeted non-metric multi-dimensional scaling (MDS)

469 analysis demonstrated that over time the leachate microbial communities became similar to

470 digestate-based communities (Fig. 5), while the microbial communities in the feedstock

471 remained distinct. Initially, through day 80 , leachate bacterial communities were distinct from

472 other communities. However, by day 112 , the communities had undergone a large shift, and by 
473 day 192, the leachate communities clearly clustered with inoculum and digested waste

474 communities (Fig. 5a, b). Similarly, by day 192, hydrolyzing communities in leachate converged

475 with digested waste communities, even though hydrolyzers have been considered solids-

476 associated (Fig. 5d). Interestingly, cel48 microbial communities did not cluster as tightly as the

477 bacterial or fermenting communities (Fig. 5c), which indicates that cellulose hydrolyzers are less

478 different among fresh waste, inoculum, and leachate. Thus, molecular data suggest that

479 recirculated leachate can indeed be a useful inoculum for hydrolysis after a lag period if the

480 leachate microbial communities are properly developed. Interestingly, in one of the few studies

481 to investigate microbial community dynamics in AD leachate, Degueurce et al. (2016) concluded

482 there was little transfer of microorganisms between leachate and solid waste in LBRs digesting

483 manure, and, instead, microorganisms inherently present in the manure strongly impacted reactor

484 performance. The contrasting results observed in our study may be explained by the difference in

485 feedstocks; manure often is used as an inoculum due to its high quantity of microorganisms,

486 which likely dominated reactor communities, whereas OFMSW microorganisms were readily

487 outcompeted by optimized inoculum microbes. The OFMSW feedstocks likely did not contain

488 high levels of bacteria tolerant of elevated salinity and ammonia. Additionally, lower redox in

489 the AD system likely contributed to selection of different microbes despite storage of the food

490 waste in large bins that may have become anaerobic.

491

Results also indicated that the inoculum delivery approach impacted development of

492 desired microbial communities within fresh waste during the digestion process. For LI, original

493 inoculum and 5-day digested waste formed a tight cluster when compared to fresh waste and

494 early leachate, indicating relatively successful transfer of inoculum microbes to the fresh waste

495 (Fig. 5a). However, inoculum and fresh waste layers were distinguishable from each other (Fig. 
5b). For MI, the microbial community composition grouped generally between the LI waste and

497

498

499

500

501

502

503

504

505

506

507

508

509

510

511

512

513

514

515

516

517

518

LI inoculum layers; these results suggest that thorough mixing is likely beneficial. Interestingly, the NI microbial communities generally clustered with the LI waste layer and MI, indicating that after 192 days, leachate delivered generally the same types of bacteria to the fresh waste as the solid waste inoculum. However, NI communities grouped closer to the LI fresh waste layer than the inoculum layer, consistent with the observed benefits of inoculation with digested waste.

These results are in agreement with previous research indicating that surface-attached bacteria are important for hydrolysis, particularly for cellulose (Lu et al., 2008; Wang et al., 2010). In one of the few studies to look at inoculation methods, El-Mashad et al. (2006) demonstrated that adding inoculum throughout the reactor height compared to leaving previously digested waste at the bottom of reactors increased methane generation. Thus, enhanced delivery methods (e.g., mixing) may increase hydrolysis performance further. Future research is needed to develop enhanced inoculation approaches suitable for full-scale implementation in dry digestion technologies.

\subsubsection{Identification of inhibitor-tolerant microbial phylotypes}

Bacterial-targeted 16S rRNA gene amplicon sequencing results revealed distinct phylotypes present in inoculum, leachate, and fresh waste. The highest species diversity was observed in the inoculum and one leachate sample (Shannon values of 4.7 and 3.37, respectively), whereas the lowest species diversity was observed in the other leachate sample (1.0) (Table S2). The majority ( $>95 \%$ ) of microorganisms in all samples were identified beyond the domain level (Fig. 6).

Interestingly, the microbial community in fresh waste was dominated by anaerobes, as well as microorganisms associated with food waste. At the order level, Lactobacillales accounted 
519 for over $89 \%$ of the microorganisms in the fresh waste, although its presence was less than 1 and

$5207 \%$ abundance in the leachate and inoculum, respectively. Within this order, 4 main genera

521 (Leuconostoc, Lactococcus, Weissella, and Lactobacillus) were identified (Fig. 6), all of which

522 are acid-tolerant anaerobes largely involved in the fermentation of dairy products and vegetables.

523 The dominance of these anaerobes was somewhat unexpected and could reflect the particular

524 waste utilized in this study or storage method of food waste prior to collection.

525

Although microbial communities in the leachate and inoculum were similar, differences

526 observed suggest complimentary capabilities. Bacteroidales accounted for the majority of the

527 organisms in the leachate (94 and 66\%) and comprised 37 and $42 \%$ abundance in the two

528 inoculum samples (order-level analysis not shown). Bacteroides was the dominant genus in

529 leachate and comprised over $25 \%$ of the solid waste inoculum. Bacteroides are known to be

530 cellulolytic and carbohydrate-utilizing (Wang et al., 2010). The particular species (Bacteroides

531 coprosuis) dominating the genus Bacteroides observed in our reactors was first isolated in 2005

532 from a swine-manure storage pit (Whitehead et al., 2005) and has been documented since then in

533 digesters treating municipal sludge and waste from cattle farms. Similar to the cel48 gene-

534 targeted T-RFLP data, results indicated that hydrolyzing bacteria in the form of Bacteroides

535 (which contain the cel48 gene) are present in the leachate. Based on these observations,

536 Bacteroides are likely ammonia and salinity tolerant and contribute to improved performance

537 under these conditions. Order Clostridiales, which includes Family XI, are bacteria well known

538 for their cellulolytic capabilities (Wang et al., 2010), and comprised $40 \%$ of the inoculum

539 communities, but were present at very low levels in the leachate (1 and 5\%) and fresh waste

$540(<2 \%)$. This observation is consistent with previous studies indicating Clostridia are solids-

541 associated (Lu et al., 2008; Wang et al., 2010) and may help explain observed performance 
542 improvements when solid inoculum was provided. Yard waste accounted for just over 10\% of

543 the total mass added to reactors and is a main source of cellulose in the system, and this

544 feedstock may have been hydrolyzed more completely when Clostridia were provided.

\section{4. Conclusions}

The challenges associated with inhibitory ammonia and salinity concentrations

547 encountered in AD systems can be overcome via hydrolysis seeding methods. Inoculum should 548 be established by maintaining high levels of digested waste ( $40-60 \%$ by mass) in hydrolysis

549 reactors to seed successive batches at start-up or when salinity and ammonia are observed to be 550 elevating. After a lag period, desired hydrolyzers accumulate in recirculated leachate. Thus,

551 leachate recirculation combined with digested-waste inoculum ( $\sim 10 \%$ by mass $)$ is recommended

552 for improved performance. Optimized hydrolysis may reduce capital and operating costs and 553 ultimately increase the economic viability of dry AD systems that incorporate leachate recycle.

\section{Acknowledgments}

555 This project was supported by the Environmental Research and Education Foundation (EREF)

556 and the USDA National Institute of Food and Agriculture (NIFA) Hatch project 229324. L.P.

557 Wilson was supported by a scholarship granted by EREF. The authors would like to thank Sara

558 Norris and Lucas Loetscher for guidance with reactor construction and Karen Rossmassler for

559 assistance with molecular biology analyses. Additionally, we acknowledge Hageman Earth

560 Cycle (Fort Collins, CO) and CSU Facilities for providing the feedstocks utilized in this study.

\section{References}

562 1. Ahn, H.K., Smith, M.C., Kondrad, S.L., White, J.W. 2010. Evaluation of biogas production 563 potential by dry anaerobic digestion of switchgrass-animal manure mixtures. Appl. Biochem. $564 \quad$ Biotechnol., 160(4), 965-975. 
2. APHA. 1995. Standard methods for the examination of water and wastewater. 19th ed. American Public Health Association, Washington, DC, USA.

3. Beanie, A. 2013. Solid waste district pilots dry fermentation digester. BioCycle, 54(11), 32.

4. Calli, B., Mertoglu, B., Inanc, B., Yenigun, O. 2005. Effects of high free ammonia concentrations on the performances of anaerobic bioreactors. Process Biochem., 40(3-4), 1285-1292.

5. Carucci, G., Carrasco, F., Trifoni, K., Majone, M., Beccari, M. 2005. Anaerobic digestion of food industry wastes: Effect of codigestion on methane yield. J. Environ. Eng.-ASCE, 131(7), 1037-1045.

6. Chen, Y., Cheng, J.J., Creamer, K.S. 2008. Inhibition of anaerobic digestion process: A review. Bioresour. Technol., 99(10), 4044-4064.

7. Cho, J.K., Park, S.C., Chang, H.N. 1995. Biochemical methane potential and solid-state anaerobic digestion of Korean food wastes. Bioresour. Technol., 52(3), 245-253.

8. Davidsson, A., Gruvberger, C., Christensen, T.H., Hansen, T.L., Jansen, J.L. 2007. Methane yield in source-sorted organic fraction of municipal solid waste. Waste Manage., 27(3), 406414.

9. Dearman, B., Bentham, R.H. 2007. Anaerobic digestion of food waste: Comparing leachate exchange rates in sequential batch systems digesting food waste and biosolids. Waste Manage., 27(12), 1792-1799.

10. Degueurce, A., Tomas, N., Le Roux, S., Martinez, J., Peu, P. 2016. Biotic and abiotic roles of leachate recirculation in batch mode solid-state anaerobic digestion of cattle manure. Bioresour. Technol., 200, 388-395. 
587 11. Duan, N.N., Dong, B., Wu, B., Dai, X.H. 2012. High-solid anaerobic digestion of sewage

588 sludge under mesophilic conditions: Feasibility study. Bioresour. Technol., 104, 150-156.

589 12. El-Mashad, H.M., van Loon, W.K.P., Zeeman, G., Bot, G.P.A., Lettinga, G. 2006. Effect of

590 inoculum addition modes and leachate recirculation on anaerobic digestion of solid cattle

591 manure in an accumulation system. Biosyst. Eng., 95(2), 245-254.

592 13. Han, S.K., Shin, H.S., Song, Y.C., Lee, C.Y., Kim, S.H. 2002. Novel anaerobic process for

593 the recovery of methane and compost from food waste. Water Sci. Technol., 45(10), 313-

594319.

595 14. Kayhanian, M. 1994. Performance of a high-solids anaerobic-digestion process under various

596 ammonia concentrations. J. Chem. Technol. Biotechnol., 59(4), 349-352.

597 15.Lefèvre, E., Pereyra, L.P., Hiibel, S.R., Perrault, E.M., De Long, S.K., Reardon, K.F.,

598 Pruden, A. 2013. Molecular assessment of the sensitivity of sulfate-reducing microbial

599 communities remediating mine drainage to aerobic stress. Water Res., 47(14), 5316-5325.

600 16. Lin, J., Zuo, J.E., Gan, L.L., Li, P., Liu, F.L., Wang, K.J., Chen, L., Gan, H.N. 2011. Effects

601 of mixture ratio on anaerobic co-digestion with fruit and vegetable waste and food waste of

602 China. J. Environ. Sci., 23(8), 1403-1408.

603 17. Lu, F., He, P.J., Hao, L.P., Shao, L.M. 2008. Impact of recycled effluent on the hydrolysis

604 during anaerobic digestion of vegetable and flower waste. Water Sci. Technol., 58(8), 1637-

$605 \quad 1643$.

606 18. Mata-Alvarez, J., Mace, S., Llabres, P. 2000. Anaerobic digestion of organic solid wastes.

607 An overview of research achievements and perspectives. Bioresour. Technol., 74(1), 3-16. 
19. Nagao, N., Tajima, N., Kawai, M., Niwa, C., Kurosawa, N., Matsuyama, T., Yusoff, F.M., Toda, T. 2012. Maximum organic loading rate for the single-stage wet anaerobic digestion of food waste. Bioresour. Technol., 118, 210-218.

20. Najafpour, G.D., Zinatizadeh, A.A.L., Mohamed, A.R., Isa, M.H., Nasrollahzadeh, H. 2006. High-rate anaerobic digestion of palm oil mill effluent in an upflow anaerobic sludge-fixed film bioreactor. Process Biochem., 41(2), 370-379.

21. Omil, F., Mendez, R., Lema, J.M. 1995. Anaerobic treatment of saline wastewaters under high sulphide and ammonia content. Bioresour. Technol., 54(3), 269-278.

22. Owen, W.F., Stuckey, D.C., Healy, J.B., Young, L.Y., McCarty, P.L. 1979. Bioassay for monitoring biochemical methane potential and anaerobic toxicity. Water Res., 13(6), 485492.

23. R Core Team. 2012. R: A language and environment for statistical computing, R Foundation for Statistical Computing. Vienna, Austria.

24. Rees, G.N., Baldwin, D.S., Watson, G.O., Perryman, S., Nielsen, D.L. 2004. Ordination and significance testing of microbial community composition derived from terminal restriction fragment length polymorphisms: application of multivariate statistics. Antonie Van Leeuwenhoek Int. J. Gen. Mol. Microbiol., 86(4), 339-347.

25. Shahriari, H., Warith, M., Hamoda, M., Kennedy, K.J. 2012. Effect of leachate recirculation on mesophilic anaerobic digestion of food waste. Waste Manage., 32(3), 400-403.

26. Song, Y.C., Kwon, S.J., Woo, J.H. 2004. Mesophilic and thermophilic temperature co-phase anaerobic digestion compared with single-stage mesophilic- and thermophilic digestion of sewage sludge. Water Res., 38(7), 1653-1662. 
27. Sundquist, A., Bigdeli, S., Jalili, R., Druzin, M.L., Waller, S., Pullen, K.M., El-Sayed, Y.Y., Taslimi, M.M., Batzoglou, S., Ronaghi, M. 2007. Bacterial flora-typing with targeted, chipbased Pyrosequencing. BMC Microbiol., 7.

28. Sung, S.W., Liu, T. 2003. Ammonia inhibition on thermophilic anaerobic digestion. Chemosphere, 53(1), 43-52.

29. Turnbaugh, P.J., Hamady, M., Yatsunenko, T., Cantarel, B.L., Duncan, A., Ley, R.E., Sogin, M.L., Jones, W.J., Roe, B.A., Affourtit, J.P., Egholm, M., Henrissat, B., Heath, A.C., Knight, R., Gordon, J.I. 2009. A core gut microbiome in obese and lean twins. Nature, 457(7228), $480-4$.

30. Voelklein, M.A., Jacob, A., Shea, R.O., Murphy, J.D. 2016. Assessment of increasing loading rate on two-stage digestion of food waste. Bioresour. Technol., 202, 172-180.

31. Wang, H., Vuorela, M., Keranen, A.L., Lehtinen, T.M., Lensu, A., Lehtomaki, A., Rintala, J. 2010. Development of microbial populations in the anaerobic hydrolysis of grass silage for methane production. FEMS Microbiol. Ecol., 72(3), 496-506.

32. Whitehead, T.R., Cotta, M.A., Collins, M.D., Falsen, E., Lawson, P.A. 2005. Bacteroides coprosuis sp. nov., isolated from swine-manure storage pits. Int. J. Syst. Evol. Microbiol., 55, 2515-2518.

33. Wilson, L.P., De Long, S.K. 2016. Stress impacts microbial community responses to feedstock changes during bioenergy generation. In preparation.

34. Wilson, L.P., Loetscher, L.H., Sharvelle, S.E., De Long, S.K. 2013. Microbial community acclimation enhances waste hydrolysis rates under elevated ammonia and salinity conditions. Bioresour. Technol., 146, 15-22. 
35. Xu, S.Y., Karthikeyan, O.P., Selvam, A., Wong, J.W.C. 2012. Effect of inoculum to substrate ratio on the hydrolysis and acidification of food waste in leach bed reactor. Bioresour. Technol., 126, 425-430.

36. Xu, S.Y., Karthikeyan, O.P., Selvam, A., Wong, J.W.C. 2014. Microbial community distribution and extracellular enzyme activities in leach bed reactor treating food waste: Effect of different leachate recirculation practices. Bioresour. Technol., 168, 41-48.

37. Xu, S.Y., Lam, H.P., Karthikeyan, O.P., Wong, J.W.C. 2011. Optimization of food waste hydrolysis in leach bed coupled with methanogenic reactor: Effect of $\mathrm{pH}$ and bulking agent. Bioresour. Technol., 102(4), 3702-3708.

38. Yan, B.H., Selvam, A., Wong, J.W.C. 2014. Application of rumen microbes to enhance food waste hydrolysis in acidogenic leach-bed reactors. Bioresour .Technol., 168, 64-71.

39. Yi, J., Dong, B., Jin, J.W., Dai, X.H. 2014. Effect of increasing total solids contents on anaerobic digestion of food waste under mesophilic conditions: performance and microbial characteristics analysis. Plos One, 9(7).

40. Zhang, B., He, P.J., Lu, F., Shao, L.M., Wang, P. 2007. Extracellular enzyme activities during regulated hydrolysis of high-solid organic wastes. Water Res., 41(19), 4468-4478.

41. Zhang, R.H., El-Mashad, H.M., Hartman, K., Wang, F.Y., Liu, G.Q., Choate, C., Gamble, P. 2007. Characterization of food waste as feedstock for anaerobic digestion. Bioresour. Technol., 98(4), 929-935.

\section{Figure Captions}

Fig 1. Reactor configuration for determining performance at start-up (a). Plan view of LBR depicting spacing of leachate distribution ports (b). Reactor configuration for determining performance over time (c). Configurations include leach bed reactors (LBRs), leachate storage tank (LST), and a fixed film (FF) 
reactor. Arrows depict leachate flow path. LBR schematic depicting layered inoculum and fresh waste (d).

Fig. 2. VS reduction as a function of percentage of inoculum at start-up (a) and over time (b). At start-up (a), reactors were seeded with acclimated $(\boldsymbol{\Delta})$ and unacclimated $(\boldsymbol{\square})$ inoculum operating under elevated ammonia and salinity. Three batches (starting on days 0,16 , and 32) were run for each percentage. Over time (b), reactors were seeded with unacclimated inoculum under low ammonia $(\bullet)$ to demonstrate optimal reactor performance without inhibition or acclimated inoculum under elevated ammonia and salinity $(\bullet)$. Multiple data points at each percentage demonstrate results for successive batches (a and b). Data points and error bars represent average performance and standard deviation for the set of triplicate reactors for a single batch (b only). Days of operation are indicated at the top of the figure.

Fig. 3. Long-term performance data for multi-stage reactors operating under elevated ammonia and salinity ( $\sim 3.5 \mathrm{~g}$ TAN/L and $45 \mathrm{mS} / \mathrm{cm}$ ) at a retention time of 16 days. (a) VFA concentrations and (b) methane yield are shown for a range of acclimated inoculum percentages over time. Inoculum percentages are noted at the top of each graph section. Vertical lines indicate the end of each batch and start of next bacth. 2 batches were run for $60 \%, 20 \%$ and $0 \%$ and 3 batches were run for $40 \%$ and $10 \%$. Additional batches were run when the first two batches did not produce similar results.

Fig. 4. Comparison of quantities of bacterial 16S rRNA genes added to leach beds via acclimated inoculum and leachate recirculation throughout a 16-day batch period. The assay utilized targets Bacteria and avoids methanogen detection. Leachate and inoculum analyzed were collected on day 192. Thus, for all of the inoculum percentages (10-60\%), bacterial $16 \mathrm{~S}$ rRNA gene quantities were estimated based on a single sample to eliminate the impact of changes over time. The amount of fresh waste added to each reactor remained constant over time, and the amount of inoculum was adjusted accordingly. Error bars correspond to standard deviations for qPCR reactions run on DNA extracted from quintuplicate samples. 
702 Fig. 5. MDS plots based on (a) 16S rRNA gene-targeted, (b) enlarged section of plot (a), (c) hydA gene703 targeted, and (d) cel48 gene-targeted T-RFLP analysis.

704

705 Fig. 6. Relative genus-level abundance of 16S rRNA bacterial-targeted OTUs based on Illumina MiSeq 706 sequencing. Higher taxonomic levels are given when genus-level identification was not possible. Label

707 "Other Bacteria" indicates grouped phylotypes that individually represented less than 5\% of the relative 708 abundance. Two representative samples each of inoculum, leachate, and fresh waste were chosen for 709 analysis. Leachate and inoculum analyzed were collected on day 192. 
(a)
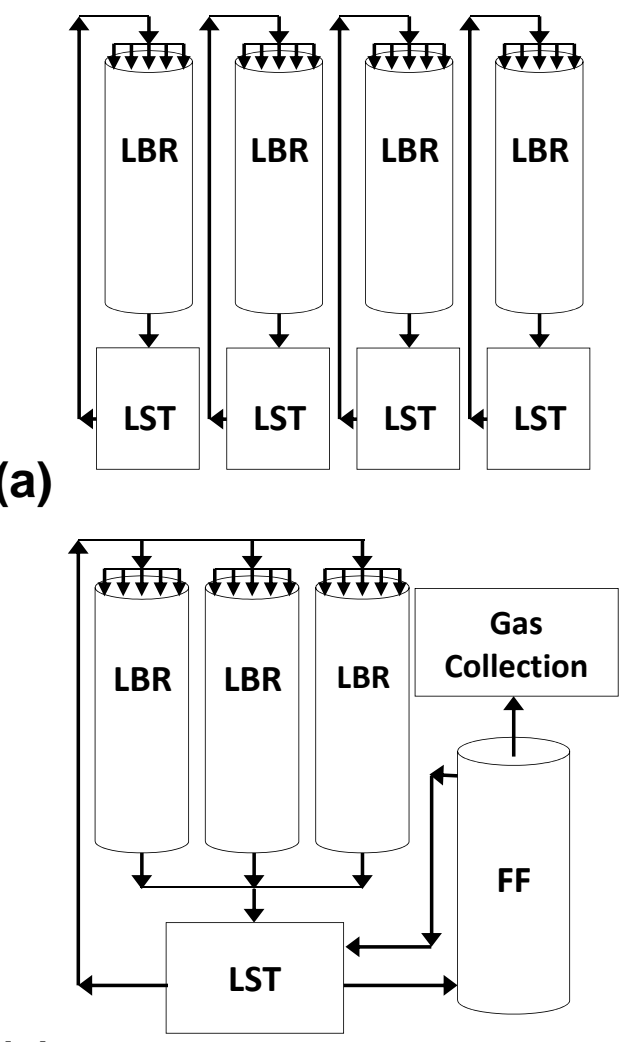

(c)

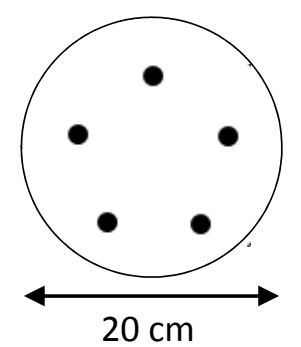

(b)

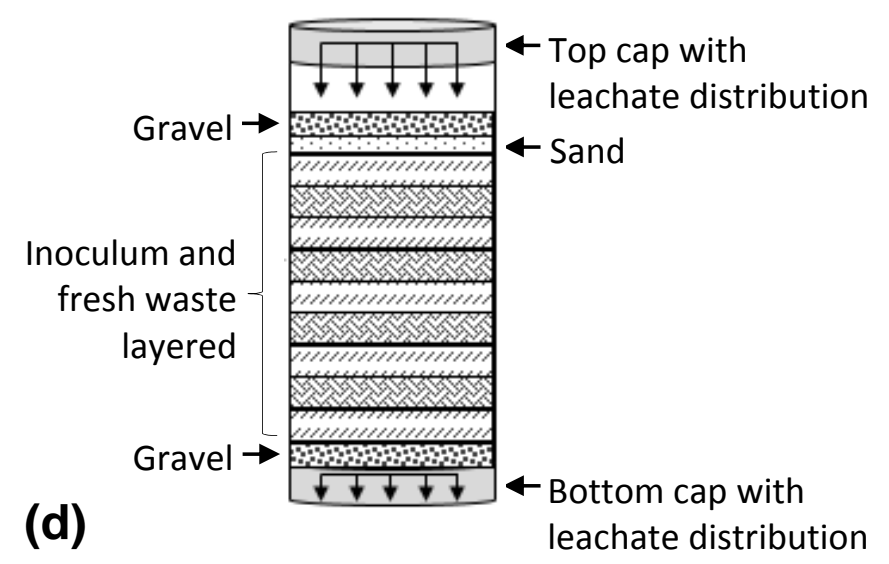

Fig. 1 

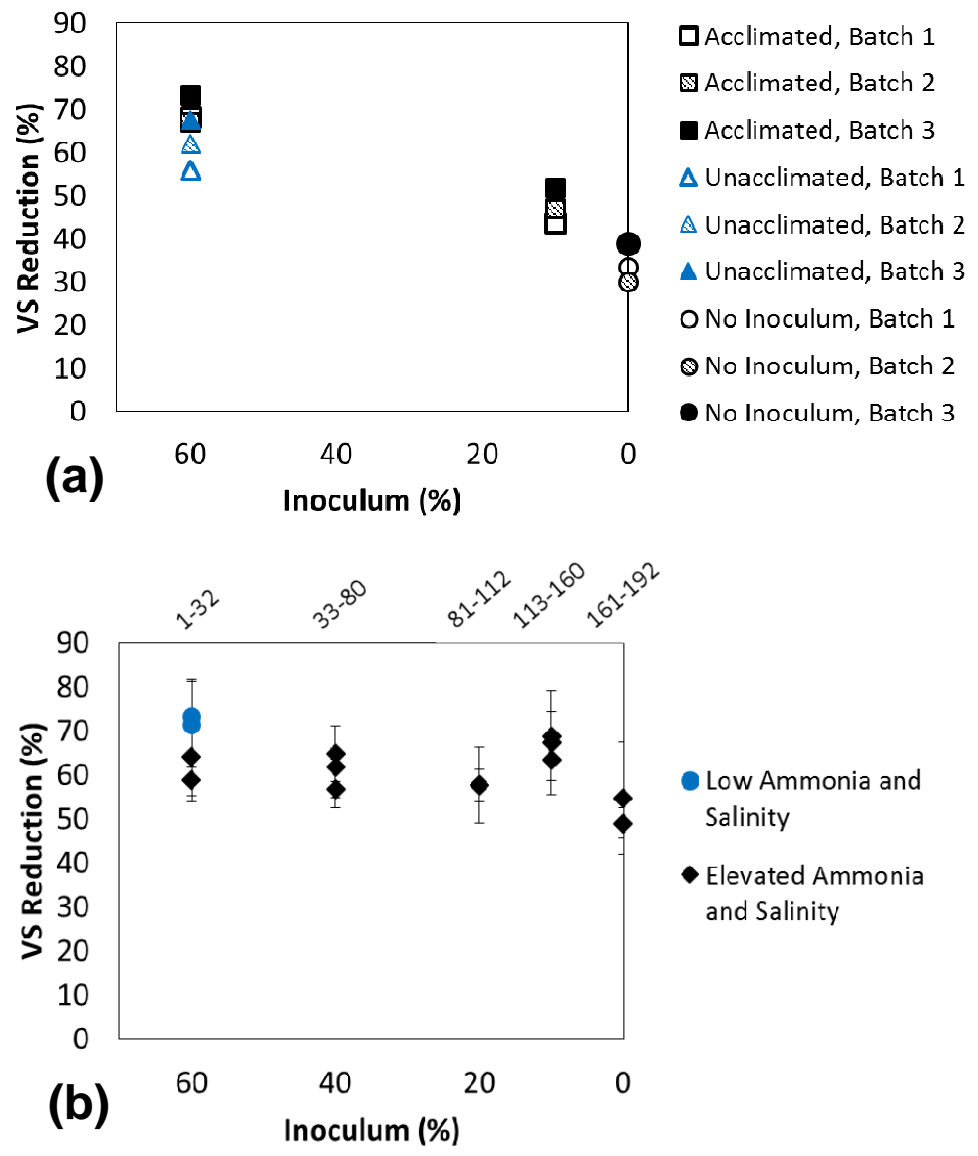

Fig. 2 


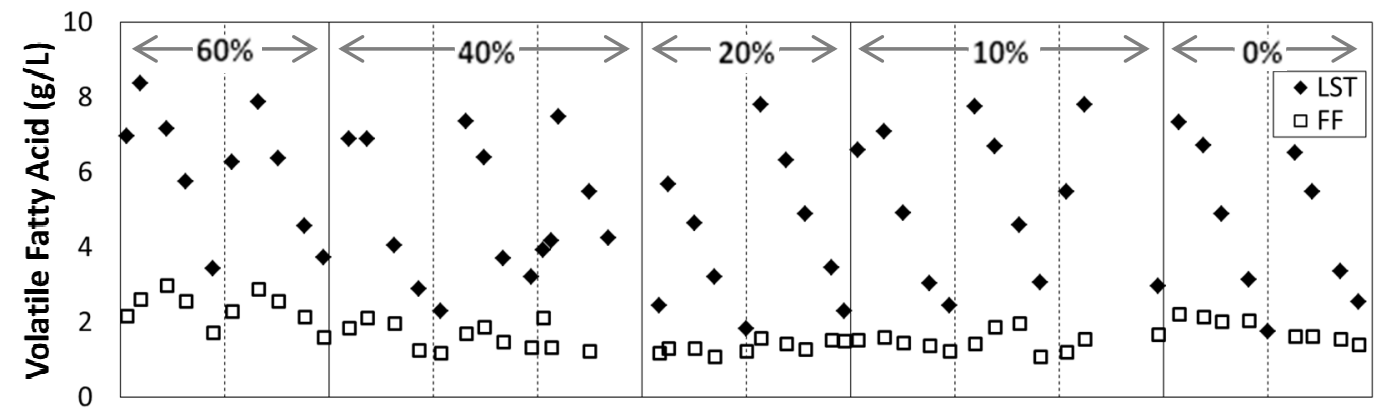

(a) $\begin{array}{lllllllllllllllllllll} & 0 & 10 & 20 & 30 & 40 & 50 & 60 & 70 & 80 & 90 & 100 & 110 & 120 & 130 & 140 & 150 & 160 & 170 & 180 & 190\end{array}$

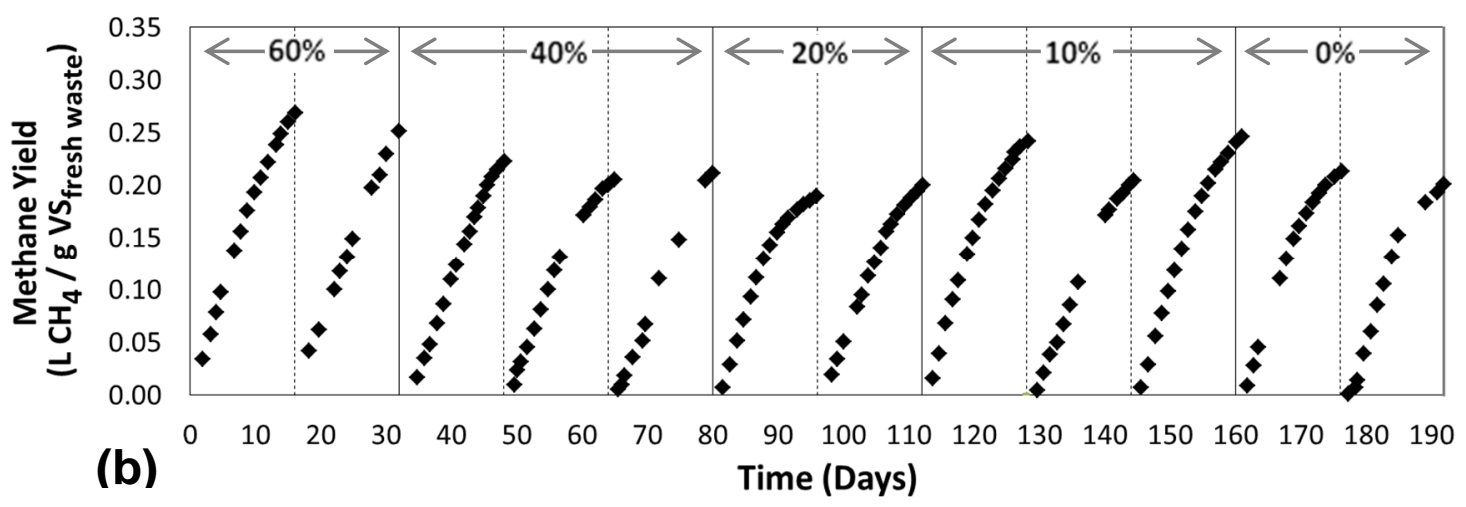

Fig. 3 


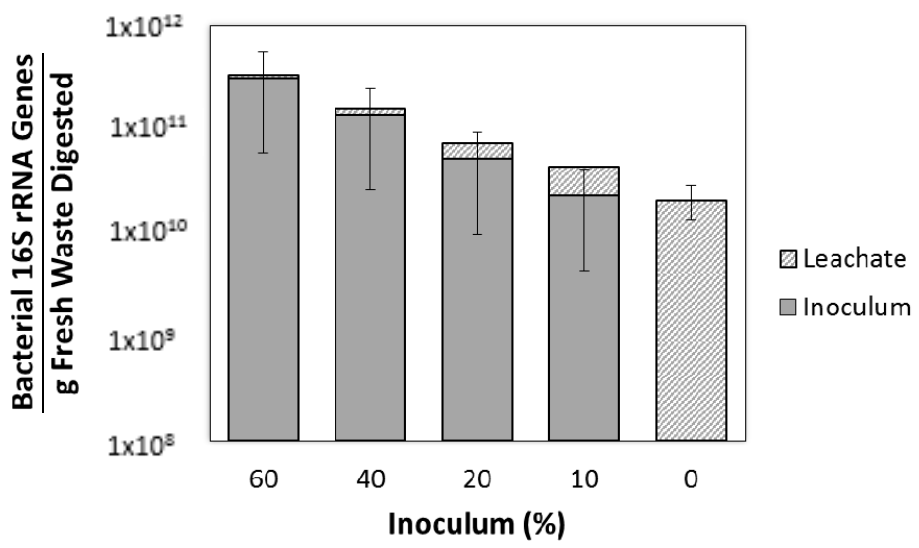

Fig. 4 

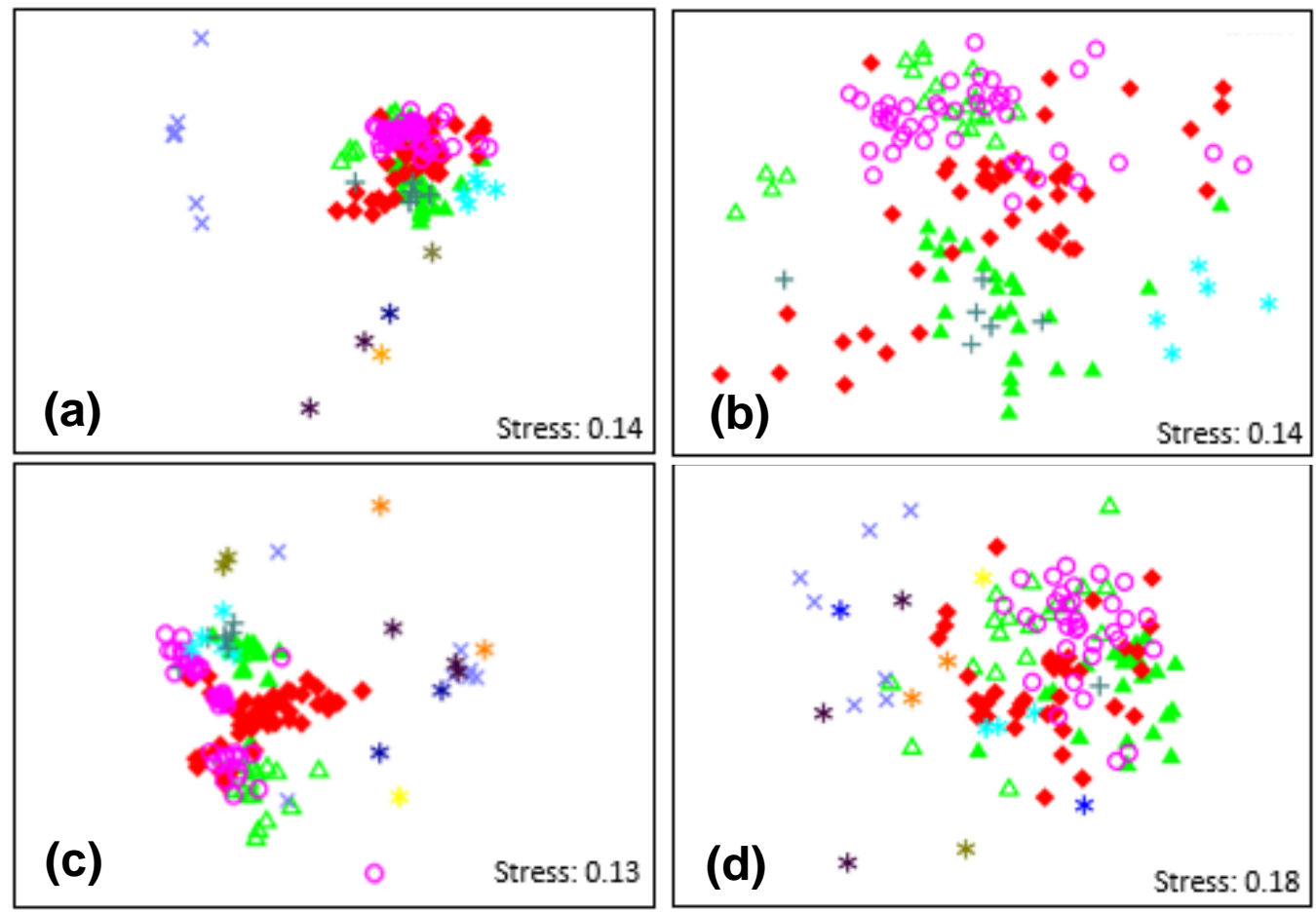

$\times$ Fresh waste $\quad+$ Original inoculum

Leachate over time:

* Day 16 (60\%, batch 1$)$

* Day $32(60 \%$, batch 2$)$

Day 48 (40\%, batch 1$)$

* Day $80(20 \%$, batch 1$)$

* Day $112(10 \%$, batch 1$)$

* Day 192 (0\%, batch 2)

Waste after a 5-day digestion period operated with leachate from day 192:

A LI: Inoculum layer

$\triangle$ LI: Fresh waste layer

- MI: Fresh waste mixed with inoculum

- NI: Fresh waste (without inoculum)

Fig. 5 


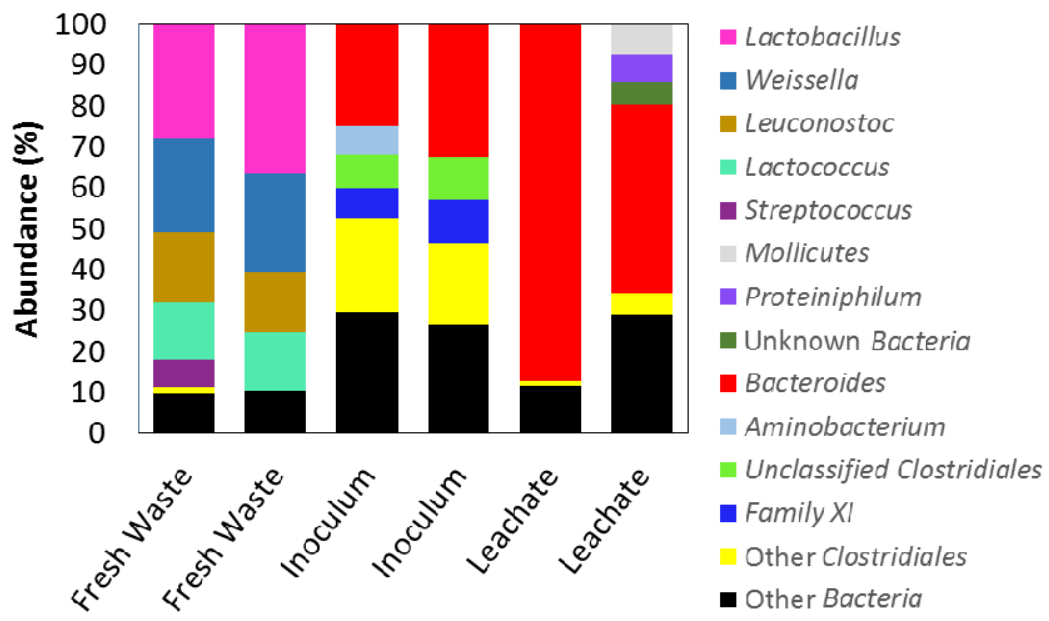

Fig. 6 